\section{A produção cientifica publicada pelo Instituto Oswaldo Cruz no período 1900 a 1917: um estudo exploratório}

Instituto Oswaldo

Cruz scientific publication from 1900 to 1917 , an exploratory study
Wanda Latmann Weltman

Biblioteca da Casa de Oswaldo Cruz Av. Brasil, 4.036 sala 415

21040-361 Rio de Janeiro — RJ Brasil weltman@coc.fiocruz.br
WELTMAN, W. L.: 'A produção científica publicada pelo Instituto Oswaldo Cruz no período 1900-17: um estudo exploratório'. História, Ciências, Saúde-Manguinhos, Rio de Janeiro, vol. 9(1):159-86, jan.-abr. 2002.

O presente trabalho é um estudo exploratório sobre a produção científica publicada pelo Instituto Oswaldo Cruz (IOC) no período 1900-17. Busca-se caracterizar a produção inicial do instituto e o desempenho de seus cientistas no aspecto informacional. Para caracterizar essa produção são utilizados dados de publicação e emprega-se a análise de citação como indicativo de uso. Por meio da comparação entre os dados de publicação e os de citação, avalia-se, ainda que parcialmente, o comportamento dos cientistas do IOC na qualidade de produtores e usuários da informação. Forma-se, então, um quadro geral das áreas de atuação e de interesse dos cientistas do instituto, no período 1900-17, caracterizando assim parte de seu comportamento informacional.

PALAVRAS-CHAVE: academias e institutos, história, cientistas, publicações, comunicação científica, Instituto Oswaldo Cruz.

WELTMAN, W. L.: 'Instituto Oswaldo Cruz scientific publication from 1900 to 1917 , an exploratory study'.

História, Ciências, Saúde-Manguinhos, Rio de Janeiro, vol. 9(1):159-86, Jan.-Apr. 2002

The present article is an exploratory study on the scientific material published by Instituto Oswaldo Cruz (IOC) from 1900 to 1917. It aims at characterizing the initial production of the institute and its scientists' concern with information. In order to characterize such production, publication data and citation analysis have been used. Through a comparative analysis of publication data and their citations by other scientists, the author evaluates part of IOC scientists' behavior towards the quality of products and as information users. The present study builds up a general view of those

scientists' areas of activities and interests in the period 1900-1917 and characterizes part of their role as information producers and users

KEYWORDS: scientific publication, production of information, information users, IOC, IOC bistory. 
$\mathrm{N}^{\circ}$ o início do século XX, o Instituto Oswaldo Cruz (IOC) destacava-se entre as instituições de pesquisa na área das ciências biomédicas e da saúde pública no Brasil. Alguns historiadores (Stepan, 1976; Benchimol, 1990; Schwartzman, 1979) consideram que o IOC representou um marco de rompimento na maneira de se fazer ciência no Brasil. Seus cientistas não foram apenas consumidores de idéias e conhecimentos europeus, eles produziram conhecimentos originais na área das ciências biomédicas.

Uma das possíveis razões para essa produção de conhecimentos originais estaria ligada ao fato de as pesquisas empreendidas no IOC estarem voltadas para a resolução de problemas brasileiros (Stepan, 1976). Na busca de soluções para esses problemas, foram encontradas saídas originais que podiam ser aplicadas não somente a problemas brasileiros. Isso atraiu inclusive cientistas estrangeiros para o instituto, na época, interessados em conhecer as pesquisas ali realizadas (Stepan, 1976; Benchimol, 1990).

Além disso, um papel importante que o IOC desempenhou no período foi o de formador de massa crítica, graças ao grupo de cientistas que conseguiu reunir em torno de suas pesquisas. Apesar da importância de Manguinhos no cenário nacional, os mesmos autores citados apontam para o fato de que outras instituições desenvolveram atividades científicas importantes, antes da criação do IOC, como a Faculdade de Medicina do Rio de Janeiro, o Instituto Bacteriológico de São Paulo e o Instituto Pasteur do Rio de Janeiro.

Em 1908, o IOC firmou-se como a principal instituição de pesquisa científica no Brasil. Seu grande desenvolvimento estava relacionado ao modelo institucional por ele adotado, que se alicerçava em três pontos: ensino, produção e pesquisa. O instituto preocupava-se com a formação de quadros profissionais, produzia soros e vacinas e realizava pesquisa básica e aplicada. Tudo isso, mais a autonomia financeira que alcançou no período, garantiu-lhe um cunho de perpetuação e não de imediatismo, como foi o caso de outras instituições científicas criadas na época (Stepan, 1976; Benchimol, 1990).

Estudar a formação do IOC pelas publicações de seus primeiros cientistas nos pareceu desde o início interessante pela importância da instituição no cenário científico nacional e pelo fato dela dispor de uma biblioteca onde os trabalhos publicados pelos cientistas estão, na sua maior parte, disponíveis. E, ainda, pela possibilidade de buscar mais informações acerca da constituição do instituto e contribuir para a área da ciência da informação, na qual estudos correlatos vêm se desenvolvendo.

Resgatar a atuação do IOC no seu período inicial, como instituição que se dedicava à produção, pesquisa e ensino na área das ciências biomédicas, é uma das linhas de pesquisa histórica que vem sendo desenvolvida pela Casa de Oswaldo Cruz (COC). Este estudo - na área de comunicação científica — traz uma 
contribuição da área da ciência da informação para essa linha de pesquisa.

A comunicação científica é uma especialidade da ciência da informação que estuda o processo informacional no desenvolvimento das atividades científicas (Garvey et al., 1979). Ela engloba o processo que vai desde a geração da informação, passando pela transmissão, até a recepção. Os cientistas são ao mesmo tempo produtores e usuários das informações, isto é, geradores e receptores. As informações são veiculadas através de canais de vários tipos. Todo esse processo ocorre em um ambiente específico, no caso, o contexto científico (Mikhailov et al., 1984).

Pode-se dizer que o processo da comunicação científica inicia-se quando o cientista tem a idéia de sua pesquisa, que vai avançando e se consolidando progressivamente. À proporção que a pesquisa progride, a informação vai sendo registrada, deixando aos poucos de ser algo de que só aquele primeiro cientista e seus companheiros de trabalho têm conhecimento, para difundir-se em audiências cada vez menos restritas.

O processo pode ocorrer por meio de canais formais e informais (Mikhailov, et al. 1984; Christovão, 1979). Entre as manifestações dos canais informais estariam: a troca de cartas entre cientistas, os contatos pessoais e as comunicações orais em encontros, congressos etc. Os artigos de periódicos e os livros seriam alguns dos chamados veículos formais da comunicação científica.

No estudo realizado, trabalhou-se com os canais formais da comunicação científica, uma vez que foi feito o levantamento da produção científica publicada pelos primeiros cientistas do IOC. No estudo, os cientistas são vistos tanto como produtores da informação, através dos trabalhos por eles publicados, quanto como usuários da informação, por meio do levantamento dos periódicos que citam, isto é, de parte dos documentos em que se apoiaram para realizar suas pesquisas.

Trabalhou-se aqui com dois enfoques, ao estudarmos a comunicação científica no interior do IOC: um deles foi o estudo das publicações científicas e suas relações, procurando-se caraterizar essa produção; o outro foi o estudo dos autores e seu comportamento, procurando-se identificar quem eles eram, em que área atuavam e qual o seu vínculo com a instituição.

Nesse estudo, foi utilizada a análise de citação, ferramenta da bibliometria aplicável à comunicação científica. Trabalhou-se com as referências bibliográficas contidas nos trabalhos dos cientistas do IOC, isto é, com as obras que eles citam (Narin et al., 1977; Narin et alii, 1976). Atribui-se às citações um valor de apoio, de respaldo a um novo trabalho, isto é, considera-se que um autor cita outros autores de modo que seu trabalho tenha respaldo científico e integre-se ao corpo de conhecimento já aceito - ao consenso científico. Consideraram-se, além disso, as citações como indicadores de uso (Smith, 1981), isto é, 
um autor cita aqueles autores que de alguma maneira utilizou na realização de seu trabalho.

Levou-se em conta, porém, durante nosso estudo, que as citações são somente pistas, indicativos de um comportamento informacional dado, não fornecendo, isoladamente, respostas suficientes para as questões relacionadas a esse comportamento.

\section{Metodologia}

O período escolhido para o estudo foi o de 1900-17. Ele corresponde ao início das atividades do IOC, passa pela sua consolidação institucional, com o reconhecimento oficial de seu status de Instituto de Medicina Experimental, em 1908 (Benchimol, 1990; Stepan, 1976), indo até o final da gestão de Oswaldo Cruz. Trata-se, portanto, do período de formação do instituto.

Identificaram-se primeiramente os cientistas de Manguinhos no período e foram caracterizadas suas trajetórias profissionais. Formouse, então, um cadastro de cientistas. Foram selecionados aqueles que ingressaram no instituto até 1916, incluindo-se também na seleção aqueles que ingressaram no instituto antes de 1917, como estudantes, ainda que só posteriormente tivessem entrado para os quadros da instituição. Foram selecionados apenas cientistas que tivessem pelo menos um trabalho publicado no período, já que se analisou a produção dos cientistas sob o ponto de vista da publicação.

O cadastro inclui dados sobre o nascimento e a morte dos cientistas, seus períodos de permanência no instituto, os cargos que exerceram, as especialidades nas quais atuaram, os estágios, cursos e viagens de trabalho que realizaram. Além disso, foram anexadas a esse cadastro as listas de documentos publicados por eles no período.

Os dados coletados a partir do cadastro dos cientistas e do levantamento de suas publicações, foram trabalhados em relação aos seguintes aspectos:

- Período de permanência dos cientistas no instituto.

- Atividades científicas desenvolvidas pelos cientistas no período.

- Relação entre produção do período e trabalhos encontrados na Biblioteca de Manguinhos, que reúne os trabalhos publicados por todos os pesquisadores do Instituto Oswaldo Cruz.

- Distribuição dos cientistas segundo sua produtividade no instituto, no período.

- Distribuição ano a ano dos trabalhos publicados.

- Áreas de atuação dos cientistas do instituto, no período.

- Periódicos brasileiros e estrangeiros em que publicaram artigos.

- Características desses periódicos.

- Distribuição geográfica dos artigos de periódicos publicados no exterior, no período.

- Distribuição por periódico dos artigos produzidos. 
- Relações de co-autoria dos cientistas do IOC no período.

- Caráter geral das publicações.

Quanto ao uso da análise de citação, foram assinaladas as referências bibliográficas existentes nos trabalhos, bem como as citações encontradas no corpo das publicações. Para efeito de avaliação, só foram consideradas as citações feitas de periódicos. Isto se explica pelo fato de elas terem freqüência superior às citações em relação a outro tipo de publicação, à facilidade de checagem entre periódicos citados e periódicos disponíveis na biblioteca de Manguinhos e, também, pelo fato de os periódicos serem considerados o tipo de publicação que contém informações mais atualizadas sobre as diferentes áreas de pesquisa científica. Assinalar que periódicos os cientistas do IOC citavam deu-nos uma noção de suas áreas de interesse no período.

Estabelecemos a origem geográfica dos periódicos citados segundo seus locais de publicação, e não segundo os idiomas nos quais eram publicados, entendendo o local de publicação como informação mais consistente sobre a origem dos periódicos.

Os dados coletados a partir da análise de citações foram trabalhados nos seguintes aspectos:

- Relação entre periódicos citados e periódicos disponíveis na Biblioteca de Manguinhos.

- Distribuição geográfica e por títulos de periódicos das citações feitas pelos cientistas do IOC a periódicos científicos.

\section{Resultados e discussão}

No período estudado, foram identificados 29 cientistas trabalhando no IOC. O período de sua permanência na instituição, bem como as atividades científicas por eles desenvolvidas também foram estabelecidos.

O Quadro 1A permite visualizar quem eles eram e quando ingressaram na instituição. Além dos 29, foram identificados quatro cientistas alemães que estiveram em Manguinhos, no período, trabalhando e publicando com os cientistas do IOC, o que pode explicar inclusive a ligação dos cientistas do instituto com instituições alemãs, a publicação de seus artigos em periódicos alemães e as citações que deram a publicações alemãs. Foram eles: Gustav Giemsa, Stanislas Von Prowazek, Max Hartmann e Hermann Duerck. Eles estiveram em Manguinhos nos seguintes períodos/anos:

Giemsa - de julho a dezembro de 1908, e de novo em 1912;

Prowazek — de julho de 1908 a fevereiro de 1909;

Hartmann — de maio a novembro de 1909;

Duerck - 1912.

Esses cientistas foram cadastrados, mas seus trabalhos não foram tratados. Eles interessam-nos na qualidade de interlocutores dos cientistas do IOC, aqui estiveram, ajudando na formação desses cientistas e publicando junto com eles. 
QUADRO IA

PERÍODO DE PERMANÊNCIA DOS CIENTISTAS NO INSTITUTO

\begin{tabular}{|c|c|c|c|c|c|c|c|c|c|c|c|c|c|c|c|c|c|}
\hline CIENTISTAS & 1899 & 1900 & 1901 & 1902 & 1903 & 1904 & 1905 & 1906 & 1907 & 1908 & 1909 & 1910 & 1911 & $1912 \quad 1913$ & $1914 \quad 1915$ & 1916 & 1917 \\
\hline \multicolumn{18}{|l|}{ ARAGÃO, $\mathrm{H}$. } \\
\hline \multicolumn{18}{|l|}{ BARRETO, A. L. B. } \\
\hline \multirow{2}{*}{\multicolumn{18}{|c|}{$\begin{array}{l}\text { CHAGAS C. } \\
\text { CHAVES, L. B. }\end{array}$}} \\
\hline \multirow{2}{*}{\multicolumn{18}{|c|}{ CRUZ O. CRUZ }} \\
\hline & & & & & & & & & & & & & & & & & \\
\hline \\
\hline \multicolumn{18}{|l|}{$\begin{array}{l}\text { DIAS, E. C. } \\
\text { FARIA, J. G. de }\end{array}$} \\
\hline \multicolumn{18}{|l|}{ FIGUEIREDO, C. B. de } \\
\hline \multicolumn{18}{|l|}{ FONSECA FILHO, O. da } \\
\hline \multicolumn{18}{|l|}{ FONTES, A. C. } \\
\hline \multicolumn{18}{|l|}{$\begin{array}{l}\text { GODOY, A. } \\
\text { GUERREIRO, C. }\end{array}$} \\
\hline \multicolumn{18}{|l|}{$\begin{array}{l}\text { GUERREIRO, C. } \\
\text { HORTA, P. de F. P. }\end{array}$} \\
\hline \multicolumn{18}{|l|}{ LIMA, A. M. da C. } \\
\hline \multicolumn{18}{|l|}{ LIMA, H. da R. } \\
\hline \multirow{2}{*}{\multicolumn{18}{|c|}{$\begin{array}{l}\text { LUTZ, A. } \\
\text { MACHADO, A. }\end{array}$}} \\
\hline & & & & & & & & & & & & & & & & & \\
\hline \multicolumn{18}{|l|}{ MAGALHÃES, O. de } \\
\hline \multicolumn{18}{|l|}{ MIRANDA, C. } \\
\hline \multicolumn{18}{|l|}{ MOSES, A. } \\
\hline \multicolumn{18}{|l|}{$\begin{array}{l}\text { NEIVA, A. } \\
\text { SILVA, O. D. e }\end{array}$} \\
\hline \multicolumn{18}{|l|}{$\begin{array}{l}\text { SILVA, O. D. e } \\
\text { SOUZA-ARAUJO, H. C. de }\end{array}$} \\
\hline \multicolumn{18}{|l|}{ TORRES, C. B. M. } \\
\hline \multicolumn{18}{|l|}{ TRAVASSOS, L. } \\
\hline \multirow{2}{*}{\multicolumn{18}{|c|}{$\begin{array}{l}\text { VASCONCELOS, H. F. de } \\
\text { VIANNA, G. de O. }\end{array}$}} \\
\hline & & & & & & & & & & & & & & & & & \\
\hline VILLELA, E. de A . & & & & & & & & & & & & & & & & & \\
\hline
\end{tabular}


QUADRO IB

PRODUÇÃO DOS CIENTISTAS DO IOC NO PERÍODO 1900-17: TOTAIS PUBLICADOS E LOCALIZADOS

\begin{tabular}{|c|c|c|c|}
\hline \multirow{2}{*}{$\begin{array}{l}\text { CIENTISTAS } \\
\text { PERÍODO NO IOC }\end{array}$} & \multicolumn{3}{|c|}{ TRABALHOS } \\
\hline & \multicolumn{2}{|c|}{ PUBLICADOS } & ENCONTRADOS \\
\hline 1 - ARAGÃO, H. (1903-17) & \multicolumn{2}{|c|}{48 (11 em co-autoria) } & 41 \\
\hline 2 - BARRETO, A. L. B. (1912-17) & \multicolumn{2}{|c|}{4} & 4 \\
\hline 3 - CHAGAS, C. (1902-17) & \multicolumn{2}{|c|}{45 (5 em co-autoria) } & 43 \\
\hline 4 - CHAVES, L. (1912-17) & \multicolumn{2}{|c|}{1} & 1 \\
\hline 5 - CRUZ, O. G. (1899-17) & \multicolumn{2}{|c|}{28} & 23 \\
\hline 6 - CUNHA, A. M. da (1912-17) & \multicolumn{2}{|c|}{22 (7 em co-autoria) } & 21 \\
\hline 7 - DIAS, E. C. (1900-17) & \multicolumn{2}{|c|}{9 (2 em co-autoria) } & 8 \\
\hline 8 - FARIA, J. G. de (1907-17) & \multicolumn{2}{|c|}{17 (7 em co-autoria) } & 17 \\
\hline 9 - FIGUEIREDO, C. B. de (1912-17) & \multicolumn{2}{|c|}{1 (em co-autoria) } & 1 \\
\hline 10 - FONSECA FILHO, O. da (1913-17) & \multicolumn{2}{|c|}{11 (4 em co-autoria) } & 11 \\
\hline 11 - FONTES, A. C. (1900-17) & \multicolumn{2}{|c|}{25 (2 em co-autoria) } & 20 \\
\hline 12 - GODOY, A. (1903-17) & \multicolumn{2}{|c|}{15 (4 em co-autoria) } & 13 \\
\hline 13 - GUERREIRO, C. (1911-17) & \multicolumn{2}{|c|}{3 (1 em co-autoria) } & 3 \\
\hline 14 - HORTA, P. de F. P. (1904-12) & \multicolumn{2}{|c|}{12 (1 em co-autoria)* } & 11 \\
\hline 15 - LIMA, A. M. da C. (1907-17) & \multicolumn{2}{|c|}{16 (1 em co-autoria) } & 15 \\
\hline 16 - LIMA, H. da R. (1901-10) & \multicolumn{2}{|c|}{3 (1 em co-autoria) } & 2 \\
\hline 17 - LUTZ, A. (1908-17) & \multicolumn{2}{|c|}{44 (11 em co-autoria) } & 38 \\
\hline 18 - MACHADO, A. (1909-17) & \multicolumn{2}{|c|}{9 (4 em co-autoria) } & 7 \\
\hline 19 - MAGALHÃES, O. de (1912-17) & \multicolumn{2}{|c|}{7} & 7 \\
\hline 20 - MIRANDA, C. (1914-17) & \multicolumn{2}{|c|}{2} & 1 \\
\hline 21 - MOSES, A. (1908-17) & \multicolumn{2}{|c|}{15 (1 em co-autoria) } & 14 \\
\hline 22 - NEIVA, A. (1906-17) & \multicolumn{2}{|c|}{58 (21 em co-autoria) } & 55 \\
\hline 23 - SILVA, O. D. e (1912-17) & \multicolumn{2}{|c|}{10 (2 em co-autoria) } & 10 \\
\hline 24 - SOUZA-ARAÚJO (1913-17) & \multicolumn{2}{|c|}{17} & 15 \\
\hline 25 - TORRES, C. B. M. (1913-17) & \multicolumn{2}{|c|}{7 (2 em co-autoria) } & 7 \\
\hline 26 - TRAVASSOS, L. (1910-17) & 36 & ria) & 34 \\
\hline 27 - VASCONCELOS, H. F. de (1910-17) & & ria) & 5 \\
\hline 28 - VIANNA, G. de O. (1909-14) & 22 & ria) & 18 \\
\hline 29 - VILLELA, E. de A. (1912-17) & & & 1 \\
\hline TOTAL (incluindo co-autorias) ** & 494 & 446 & \\
\hline Co-autorias entre cientistas do $I O C$ & 40 & 37 & \\
\hline TOTAL de trabalhos publicados & 454 & 409 & \\
\hline $\begin{array}{l}\text { Co-autorias entre cientistas do IOC } \\
\text { e cientistas externos } * * *\end{array}$ & 23 & 20 & \\
\hline $\begin{array}{l}\text { TOTAL de co-autorias } \\
\text { (trabalhos em colaboração) }\end{array}$ & 63 & 57 & \\
\hline Trabalhos individuais & 391 & 352 & \\
\hline
\end{tabular}

* Somente uma das co-autorias deste cientista foi computada no quadro, porque a outra ocorreu quando ele já se havia afastado do IOC. Esta segunda co-autoria foi computada apenas para o segundo autor, Lauro Travassos, que permaneceu no instituto.

** Estes trabalhos foram computados tantas vezes quantos eram seus autores.

*** Estes trabalhos possuem um autor interno, dos quadros do IOC, e um autor externo aos quadros do instituto. 
O barão de Pedro Afonso, primeiro diretor de Manguinhos, não foi selecionado para avaliação no estudo porque, além de ter se afastado do instituto no início das atividades da instituição, em 1902, não localizamos trabalho algum publicado por ele, na época.

Foram publicados, no período considerado, pelos cientistas do IOC, 454 trabalhos, sendo que 90\% deles foram encontrados. Sessenta e três trabalhos foram publicados em co-autoria, e 391 foram trabalhos individuais. Também foram encontrados $90 \%$ dos trabalhos individuais. O Quadro 1B apresenta quanto cada cientista publicou e quantos escritos foram encontrados.

Pelo Quadro 2, pode-se observar a produtividade de cada cientista no período e na condição de cientista do IOC, figurando Arthur Neiva como o mais produtivo, com 58 trabalhos produzidos em um intervalo de 12 anos.

\section{QUADRO 2}

\section{DISTRIBUIÇÃO DOS CIENTISTAS SEGUNDO SUA PRODUTIVIDADE NO IOC NO PERÍODO (1900-17)}

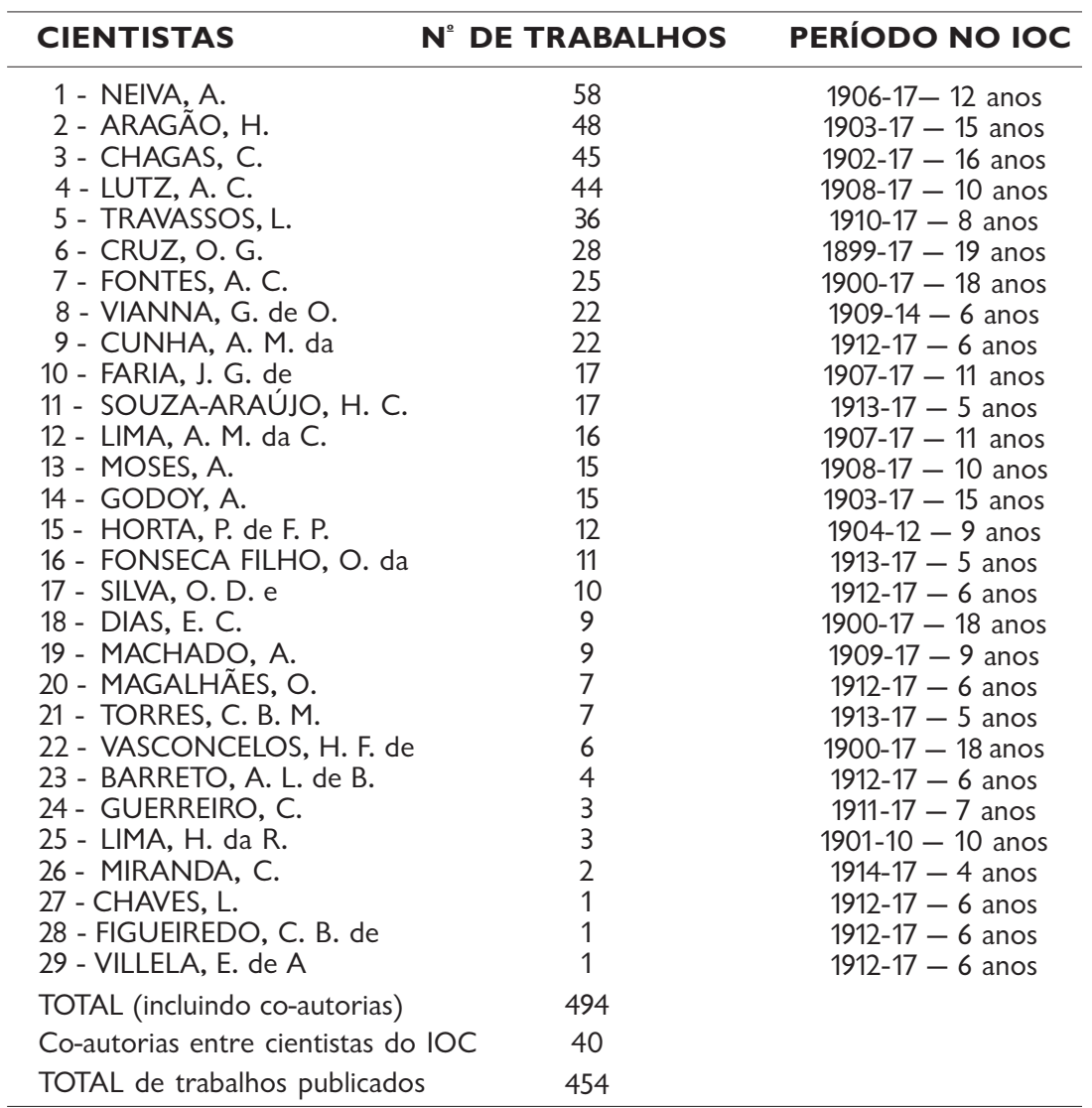

Obs.: Embora todos os trabalhos publicados em conjunto pelos cientistas do IOC, tanto no plano interno quanto no externo, estejam aqui computados, não se discriminam neste quadro os nomes dos autores externos que publicaram em colaboração com os cientistas do instituto. O tema será abordado em maiores detalhes mais adiante. 
Pelos resultados encontrados (Quadro 3), no tocante à produção publicada pelo instituto, no período, ficou claro que ela foi se condensando ano a ano, acompanhando a consolidação da instituição, com o ingresso de novos cientistas, a compra de novos materiais, a criação de uma biblioteca, a construção de novos laboratórios e a criação das Memórias do Instituto Oswaldo Cruz.

Pôde-se também observar que, enquanto alguns cientistas publicaram assim que ingressaram no instituto, outros demoraram um ano ou mais para começar a publicar. Isso talvez se explique pelo fato de alguns cientistas terem entrado para o IOC ainda como estudantes, como foi o caso de Henrique Aragão, Olympio da Fonseca Filho, Cássio Miranda, Burle de Figueiredo, entre outros. Foi possível notar também que, embora tenha havido um crescimento constante na produção publicada pelo instituto, ao longo dos anos, esse crescimento apresentou-se, por vezes, oscilante. Não se pôde explicar essa oscilação. Acredita-se, porém, que futuras investigações sobre o tema venham responder a essa questão (Figura 1).

No que se refere às áreas de atuação dos cientistas do instituto nesse período, observamos que há uma concentração de atividades nas áreas de anatomia patológica, entomologia, micologia, helmintologia e bacteriologia, vindo em seguida as áreas de protozoologia e demais. Alguns dos cientistas atuavam em mais de uma especialidade.

Observando-se o Quadro 4, nota-se que a área que congregou o maior número de cientistas do instituto, no período em questão, foi a de anatomia patológica, o que corrobora a descrição feita pelos autores, que destacam esta como uma das áreas pioneiras da instituição (Benchimol, 1990; Fonseca Filho, 1974). A produção bibliográfica, em um total de 454 trabalhos, consistia de artigos de periódicos, capítulos de livros, monografias, relatórios, teses, comunicações a congressos e outros eventos científicos e artigos de jornais.

O total de artigos em periódicos é de 366, ou seja, 80,6\% do total de trabalhos. O Quadro 5 apresenta os periódicos brasileiros nos quais publicaram-se artigos e a quantidade publicada em cada periódico.

Publicou-se maciçamente no Brazil-Médico e nas Memórias do

1 Entende-se por 'periódico de disseminação científica' aquele que publica artigos que são fruto de pesquisa científica; 'periódico de divulgação científica' é compreendido como o que publica artigos sobre ciência para o grande público (ver HernándezCañadas, 1987). IOC. Pudemos observar, também, que a maioria dos artigos publicados por Manguinhos, no período - como era de se esperar - era de pesquisa, embora os cientistas não se descuidassem de contribuir para um melhor nível de informação por parte da sociedade como um todo, ao publicar também artigos de divulgação científica (ver Quadro 6). ${ }^{1}$ Os periódicos de divulgação científica (HernándezCañadas, 1987) em que publicaram seus artigos eram ligados às áreas de agricultura e pecuária, ou eram órgãos de divulgação de sociedades médicas. A preocupação em publicar em veículos ligados às áreas de pecuária e agricultura é coerente com a atuação que o 
QUADRO 3

TRABALHOS PUBLICADOS PELOS CIENTISTAS DO IOC

ANO A ANO

PERÍODO 1900-17

\begin{tabular}{|c|c|c|c|c|c|c|c|c|c|}
\hline $\begin{array}{l}\text { PESQUISADORES } \\
\text { (por ordem de ingresso no IOC) }\end{array}$ & 1900 & 1901 & 1902 & 1903 & 1904 & 1905 & 1906 & 1907 & $\begin{array}{l}\text { A } \\
1908\end{array}$ \\
\hline $\begin{array}{l}\text { CRUZ, O. G. - } 1899 \\
\text { VASCONCELOS, H.F. de - } 1900 \\
\text { DIAS, E. C. - } 1900 \\
\text { FONTES, A. C. - } 1900 \\
\text { LIMA, H. da R. - } 1901 \\
\text { CHAGAS, C. - } 1902 \\
\text { ARAGÃO, H. - } 1903 \\
\text { GODOY, A. - } 1903 \\
\text { HORTA, P. de F. P. - } 1904 \\
\text { NEIVA, A. - 1906 } \\
\text { LIMA, A. M. da C. - } 1907 \\
\text { FARIA, J. G. de - } 1907 \\
\text { LUTZ, A. - } 1908 \\
\text { MOSES, A. - } 1908 \\
\text { VIANNA, G. - } 1909 \\
\text { MACHADO, A. - } 1909 \\
\text { TRAVASSOS, L. - } 1910 \\
\text { GUERREIRO, C. - } 1911 \\
\text { VILLELA, E. - } 1912 \\
\text { SILVA, O. D. e - } 1912 \\
\text { MAGALHÃES, O. de - } 1912 \\
\text { BARRETO, B. - } 1912 \\
\text { CHAVES, L. - } 1912 \\
\text { CUNHA, A. M. - } 1912 \\
\text { FIGUEIREDO, C. B. - } 1912 \\
\text { FONSECA FILHO, O da - } 1913 \\
\text { SOUZA-ARAÚJO, H. C. de -1913 } \\
\text { TORRES, C. B. M. - } 1913 \\
\text { MIRANDA, C. - } 1914\end{array}$ & & 3 & 3 & $\begin{array}{l}3 \\
1 \\
1\end{array}$ & 1 & $\begin{array}{l}1 \\
1\end{array}$ & $\begin{array}{l}2 \\
2 \\
1 \\
1 \\
1 \\
1\end{array}$ & $\begin{array}{l}3 \\
2 \\
1 \\
3 \\
1\end{array}$ & $\begin{array}{l}3 \\
6 \\
1 \\
4 \\
2 \\
8\end{array}$ \\
\hline $\begin{array}{l}\text { TOTAL (incluindo co-autorias) } \\
\text { TOTAL menos } \mathrm{n}^{\circ} \text { de co-autorias } \\
\text { (entre cientistas do IOC) }\end{array}$ & $3-0$ & $3-0$ & $3-0$ & $3-0$ & $2-0$ & $3-0$ & $\begin{array}{c}11 \\
11-I\end{array}$ & $\begin{array}{l}11 \\
11-0\end{array}$ & $\begin{array}{l}28 \\
28-1\end{array}$ \\
\hline TOTAL & 3 & 3 & 3 & 3 & 2 & 3 & 10 & 11 & 27 \\
\hline
\end{tabular}

* incluindo todos os trabalhos publicados em co-autoria. 
A N O

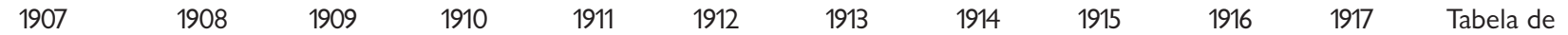
publicações por cientista*

\begin{tabular}{|c|c|c|c|c|c|c|c|c|c|c|c|}
\hline 3 & 4 & 1 & 3 & 2 & & & 3 & & 1 & & 28 \\
\hline \multirow[t]{2}{*}{2} & 1 & 1 & & & & & 2 & & & & 6 \\
\hline & & & & & 1 & 1 & 3 & 2 & & 1 & 9 \\
\hline \multirow[t]{2}{*}{1} & 2 & 4 & 2 & 1 & 2 & 2 & 4 & 1 & 1 & 2 & 25 \\
\hline & & & & & 1 & & & & & & 3 \\
\hline 3 & 3 & 10 & 7 & 5 & 4 & 5 & & 1 & 4 & & 45 \\
\hline \multirow[t]{23}{*}{1} & 6 & 5 & 1 & 6 & 5 & 6 & 2 & 1 & 5 & 8 & 48 \\
\hline & 1 & 3 & 3 & 1 & 2 & 1 & & & 2 & 2 & 15 \\
\hline & & & 1 & 7 & 2 & & & & & & 12 \\
\hline & 4 & 4 & 3 & 5 & 4 & 10 & 9 & 2 & 8 & 8 & 58 \\
\hline & & & & & & & 5 & 4 & 4 & 3 & 16 \\
\hline & 2 & 1 & 2 & 2 & 1 & 3 & 3 & & 1 & 2 & 17 \\
\hline & 8 & 3 & 2 & 2 & 9 & 6 & 5 & 4 & 1 & 4 & 44 \\
\hline & & 3 & 2 & 2 & & 3 & 2 & 1 & 2 & & 15 \\
\hline & & 1 & & 6 & 5 & 7 & 3 & & & & 22 \\
\hline & & & & 3 & & 3 & 1 & 1 & & 1 & 9 \\
\hline & & & & & & 4 & 8 & 10 & 3 & 11 & 36 \\
\hline & & & & & 1 & 1 & 1 & & & & 3 \\
\hline & & & & & & & & & & 1 & 1 \\
\hline & & & & & & 1 & 2 & 3 & 4 & & 10 \\
\hline & & & & & & 1 & 3 & & 2 & 1 & 7 \\
\hline & & & & & & & & & 1 & 3 & 4 \\
\hline & & & & & & & & 1 & & & 1 \\
\hline & & & & & & 2 & 7 & 5 & 2 & 6 & 22 \\
\hline & & & & & 1 & & & & & & 1 \\
\hline & & & & & & & & 3 & 1 & 7 & 11 \\
\hline & & & & & & & & 4 & 7 & 6 & 17 \\
\hline & & & & & & 1 & 1 & 2 & 1 & 2 & 7 \\
\hline & & & & & & & & & 1 & 1 & 2 \\
\hline 11 & 28 & 38 & 25 & 40 & 38 & 60 & 61 & 46 & 50 & 69 & 494 \\
\hline $11-0$ & $28-1$ & $38-2$ & $25-0$ & $40-2$ & $38-4$ & $60-10$ & $61-7$ & $46-4$ & $50-2$ & $69-7$ & $494-40$ \\
\hline 11 & 27 & 36 & 25 & 38 & 34 & 50 & 54 & 42 & 48 & 62 & 454 \\
\hline
\end{tabular}


Figura I

DISTRIBUIÇÃO ANUAL DOS TRABALHOS PUBLICADOS PELOS

CIENTISTAS DO IOC (1900-17)
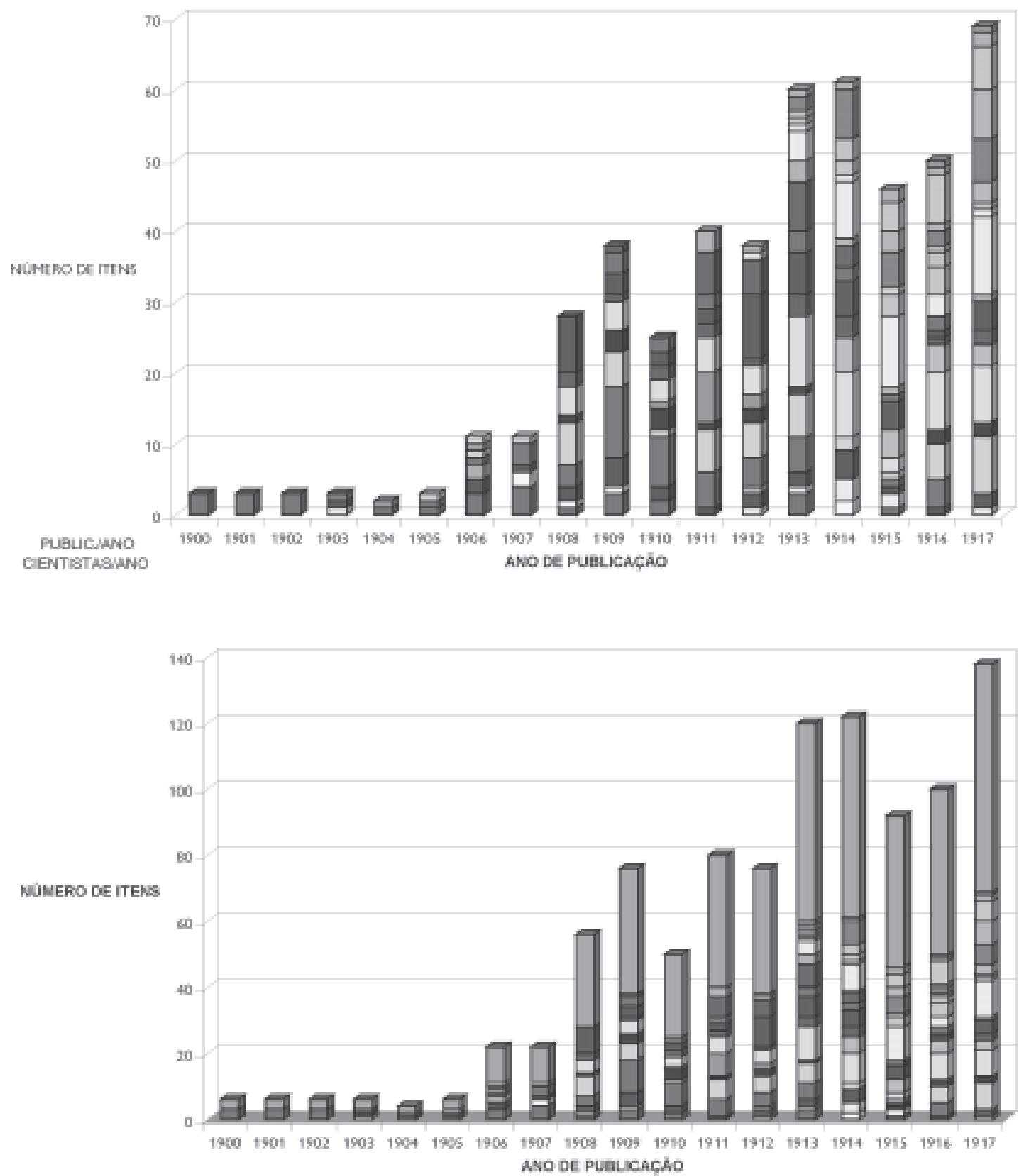
IOC teve na pesquisa e elaboração de produtos para o tratamento de doenças de animais e no combate às pragas na agricultura. Como atesta Benchimol (1990, p. 29):

...a pauta industrial de Manguinhos foi acrescida de novos produtos, destinados não apenas à terapêutica humana como à veterinária, que constituiria uma vertente de pesquisas extremamente importante para o instituto: um dos ramos clássicos da medicina pasteuriana, os estudos das epizootias, abriu-lhe novas e promissoras perspectivas de diversificar os clientes de sua produção científica, de criar bases de sustentação para ela fora do estado, junto a segmentos importantes da agropecuária.

Brazil-Médico foi o periódico que concentrou o maior número de artigos publicados, em um percentual de $44 \%$ do total de artigos. A possível razão dessa supremacia estaria no fato de ser este um periódico semanal, o que proporcionava a quem ali publicava a garantia de prioridade de suas descobertas, uma vez que estas não tardariam a chegar ao domínio público. Além disso, a revista era o principal periódico médico da cidade.

Segundo Lilia Schwarcz (1993, pp. 220, 223), Brazil-Médico, para os moldes da época, já surgiu grande. Desde seu aparecimento, contou sempre com muitos artigos, colaboradores e elevado número de anúncios. Ainda segundo a autora, "a partir de 1900, a revista assume a identidade de periódico voltado para a área de 'hygiene pública' e 'medicina tropical" - campo de atuação dos cientistas do IOC.

\section{QUADRO 4}

ÁREAS DE ATUAÇÃO DOS CIENTISTAS DO IOC (1900-17)

\begin{tabular}{|l|}
\hline (1) VIROLOGIA \\
Cunha (ver 2 e 3) \\
\hline
\end{tabular}

\begin{tabular}{|l|}
\hline (5) HELMINTOLOGIA \\
Barreto \\
Faria (ver 8 e 9) \\
Lutz \\
Travassos \\
\hline
\end{tabular}

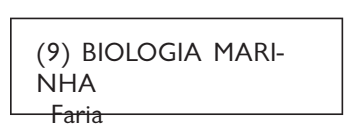

\begin{tabular}{|l|}
\hline (13) QUÍMICA \\
Godoy \\
Machado \\
\hline
\end{tabular}

(2) PARASITOLOGIA
Cunha
Fonseca (ver 11)

\begin{tabular}{l} 
(6) MICROBIOLOGIA \\
Cruz \\
Souza-Araújo \\
\hline
\end{tabular}

\begin{tabular}{|l|}
\hline (10) ANATOMIA \\
PATOLÓGICA \\
Figueiredo \\
Guerreiro \\
Lima, R. \\
Miranda \\
Silva \\
Torres \\
Vianna \\
Villela (ver 14) \\
\hline
\end{tabular}

\begin{tabular}{l} 
(3) PROTOZOOLOGIA \\
Aragão \\
Chagas \\
Cunha \\
\hline
\end{tabular}

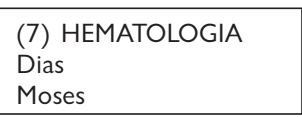

\section{(11) MICOLOGIA}

Fonseca

Horta

Lutz

Magalhães

Vasconcelos

(14) CLÍNICA

Villela

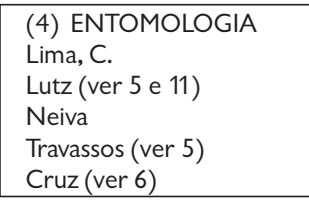

\begin{tabular}{|l|}
\hline (8) BACTERIOLOGIA \\
Faria \\
Fontes (ver 12) \\
Lima, R. (ver10) \\
Vasconcelos (ver 11) \\
\hline
\end{tabular}

(12) IMUNOLOGIA

Fontes

Machado (ver 13)

(15) ADMINISTRAÇÃO Chaves 
QUADRO 5

PERIÓDICOS BRASILEIROS ONDE OS CIENTISTAS DO IOC PUBLICARAM SEUS ARTIGOS (1900-17)

\begin{tabular}{llrr}
\hline No DE ORDEM & PERIÓDICOS & No DE ARTIGOS \\
\cline { 2 - 3 } & & $\mathbf{f}$ & $\%$ \\
\hline 1 & Brazil-Médico & 145 & $(44 \%)$ \\
2 & Memórias do IOC & 132 & $(40 \%)$ \\
3 & Rev. Med. de São Paulo & 11 & $(3,3 \%)$ \\
4 & Arch. Bras. de Med. & 9 & $(2,7 \%)$ \\
5 & Rev. de Vet. e Zootecnia & 4 & $(1,2 \%)$ \\
6 & Bol. Soc. Bras. de Sci. & 4 & $(1,2 \%)$ \\
7 & Rev. Soc. Bras. de Sci. & 3 & $(0,9 \%)$ \\
8 & Ann. Paulista de Med. e Cir. & 2 & $(0,6 \%)$ \\
9 & Arch. Mus. Nac. & 2 & $(0,6 \%)$ \\
10 & Arch. Esc. Sup. Agr. Med. Vet. & 2 & $(0,6 \%)$ \\
11 & Arch. Soc. Med. Cir. S. Paulo & 2 & $(0,6 \%)$ \\
12 & Impr. Médica de S. Paulo & 2 & $(0,6 \%)$ \\
13 & Semana Med. & 1 & $(0,3 \%)$ \\
14 & Gaz. Med. da Bahia & 1 & $(0,3 \%)$ \\
15 & Ann. Acad. Med. RJ & 1 & $(0,3 \%)$ \\
16 & Paraná Médico & 1 & $(0,3 \%)$ \\
17 & Rev. Med. Minas & 1 & $(0,3 \%)$ \\
18 & A Lavoura & 1 & $(0,3 \%)$ \\
19 & Criador Paul. & 1 & $(0,3 \%)$ \\
20 & Bol. Minist. Agr. Ind. Com. & 1 & $(0,3 \%)$ \\
20 & Rev. Soc. Sci. de S. Paulo & 1 & $(0,3 \%)$ \\
21 & Arch. Bras. de Psychiatria, Neurologia e Med. Legal & 1 & $(0,3 \%)$ \\
22 & Chácaras. Quintaes & 1 & $(0,3 \%)$ \\
24 & Patologia Geral & 1 & $(0,3 \%)$ \\
\hline TOTAL & & 330 \\
\hline
\end{tabular}

QUADRO 6

CARACTERÍSTICAS DOS PERIÓDICOS BRASILEIROS

NOS QUAIS OS CIENTISTAS DO IOC

PUBLICARAM SEUS ARTIGOS (1900-17)

\begin{tabular}{ccccc}
\hline $\begin{array}{c}\text { TítULO } \\
\text { DO } \\
\text { PERIÓDICO }\end{array}$ & $\begin{array}{c}\text { ANO } \\
\text { INÍCIO-FIM DE } \\
\text { PUBLICAÇÕES }\end{array}$ & $\begin{array}{c}\text { NÚMERO } \\
\text { DE } \\
\text { ARTIGOS }\end{array}$ & $\begin{array}{c}\text { TIPO } \\
\text { DE } \\
\text { PERIÓDICO }\end{array}$ & EDITOR \\
\hline $\begin{array}{c}\text { Ann. Acad. Nac. Med. } \\
\text { do Rio de Janeiro }\end{array}$ & $\begin{array}{c}1885-1918 \\
\text { continua como Bol. da } \\
\text { Acad. Nac. Med. R.J. }\end{array}$ & 1 & $\begin{array}{c}\text { Disseminação } \\
\text { científica }\end{array}$ & $\begin{array}{c}\text { Acad. Nac. de } \\
\text { Medicina do Rio de } \\
\text { Janeiro }\end{array}$ \\
$\begin{array}{c}\text { Ann. Paulista de } \\
\text { Medicina e Cir. }\end{array}$ & $1913-$ & 2 & $\begin{array}{c}\text { Disseminação } \\
\text { científica }\end{array}$ & $\begin{array}{c}\text { Real e Ben. Soc. } \\
\text { Portuguesa de Benef. } \\
\text { de SP }\end{array}$ \\
Arch. Bras. de Med. & $1911-$ & 9 & $\begin{array}{c}\text { Disseminação } \\
\text { científica }\end{array}$ & ECN \\
\end{tabular}


QUADRO 6 (cont.)

\begin{tabular}{|c|c|c|c|c|}
\hline $\begin{array}{c}\text { TÍTULO } \\
\text { DO } \\
\text { PERIÓDICO }\end{array}$ & $\begin{array}{l}\text { ANO } \\
\text { INÍCIO-FIM DE } \\
\text { PUBLICAÇÕES }\end{array}$ & $\begin{array}{l}\text { NÚMERO } \\
\text { DE } \\
\text { ARTIGOS }\end{array}$ & $\begin{array}{c}\text { TIPO } \\
\text { DE } \\
\text { PERIÓDICO }\end{array}$ & EDITOR \\
\hline $\begin{array}{c}\text { Arch. Bras. de } \\
\text { Psychiatria Neurologia } \\
\text { e Med. Legal }\end{array}$ & $1905-20$ & 1 & $\begin{array}{l}\text { Disseminação } \\
\text { científica }\end{array}$ & $\begin{array}{l}\text { Soc. Bras. de Neurol. } \\
\text { Psiq. e Med. }\end{array}$ \\
\hline $\begin{array}{c}\text { Arch. Esc. Sup. Agr. } \\
\text { Med. Vet. }\end{array}$ & 1917-33 & 2 & $\begin{array}{l}\text { Disseminação } \\
\text { científica }\end{array}$ & $\begin{array}{c}\text { Escola Superior de } \\
\text { Agricultura e } \\
\text { Medicina Veterinária } \\
\text { (Niterói) }\end{array}$ \\
\hline $\begin{array}{l}\text { Arch. do Mus. Nac. do } \\
\text { Rio de Janeiro }\end{array}$ & 1876-1981 (?) & 2 & $\begin{array}{l}\text { Disseminação } \\
\text { científica }\end{array}$ & Museu Nacional \\
\hline $\begin{array}{l}\text { Arch. Soc. Med. } \\
\text { Cir. São Paulo }\end{array}$ & $1910-14$ & 2 & $\begin{array}{l}\text { Disseminação } \\
\text { científica }\end{array}$ & $\begin{array}{l}\text { Sociedade de } \\
\text { Medicina e Cirurgia } \\
\text { de São Paulo }\end{array}$ \\
\hline $\begin{array}{l}\text { Bol. Minist. Agr. Ind. } \\
\text { Com. }\end{array}$ & $\begin{array}{l}\text { 1912-30 } \\
\text { continua como Bol. } \\
\text { Minist. da Agricultura }\end{array}$ & 1 & $\begin{array}{c}\text { Divulgação } \\
\text { científica na área de } \\
\text { agricultura }\end{array}$ & $\begin{array}{l}\text { Ministério da } \\
\text { Agricultura, Indústria } \\
\text { e Comércio }\end{array}$ \\
\hline $\begin{array}{l}\text { Bol. Soc. Bras. } \\
\text { Dermat. }\end{array}$ & $1912-19$ & 4 & $\begin{array}{l}\text { Divulgação } \\
\text { científica, órgão de } \\
\text { divulgação dos } \\
\text { trabalhos da } \\
\text { sociedade }\end{array}$ & $\begin{array}{l}\text { Sociedade Brasileira } \\
\text { de Dermatologia }\end{array}$ \\
\hline Brazil-Médico & $1887-71$ & 145 & $\begin{array}{l}\text { Disseminação } \\
\text { científica }\end{array}$ & $\begin{array}{c}\text { Serviço de } \\
\text { Reumatologia, } \\
\text { Policlínica Geral do } \\
\text { Rio de Janeiro }\end{array}$ \\
\hline Chácaras e Quintaes & $\begin{array}{c}1900-70 \\
\text { A partir de } 1970 \text { passa } \\
\text { a se chamar Avicultura } \\
\text { Industrial }\end{array}$ & 1 & $\begin{array}{l}\text { Divulgação } \\
\text { científica }\end{array}$ & Chácaras e Quintaes \\
\hline Criador Paulista & $1906-$ & 1 & $\begin{array}{l}\text { Divulgação } \\
\text { científica para } \\
\text { pecuaristas }\end{array}$ & $\begin{array}{c}\text { Secretaria de } \\
\text { Agricultura de São } \\
\text { Paulo }\end{array}$ \\
\hline Gaz. Med. da Bahia & $1866-1976$ & 1 & $\begin{array}{l}\text { Disseminação } \\
\text { científica }\end{array}$ & $\begin{array}{l}\text { Fac. de Med. da Univ. } \\
\text { Fed. da Bahia }\end{array}$ \\
\hline
\end{tabular}


QUADRO 6 (cont.)

\begin{tabular}{|c|c|c|c|c|}
\hline $\begin{array}{c}\text { TÍTULO } \\
\text { DO } \\
\text { PERIÓDICO }\end{array}$ & $\begin{array}{l}\text { ANO } \\
\text { INÍCIO-FIM DE } \\
\text { PUBLICAÇÕES }\end{array}$ & $\begin{array}{l}\text { NÚMERO } \\
\text { DE } \\
\text { ARTIGOS }\end{array}$ & $\begin{array}{c}\text { TIPO } \\
\text { DE } \\
\text { PERIÓDICO }\end{array}$ & EDITOR \\
\hline $\begin{array}{l}\text { Imprensa Médica de } \\
\text { São Paulo }\end{array}$ & -1914 & 2 & $\begin{array}{l}\text { Divulgação } \\
\text { científica }\end{array}$ & \\
\hline A Lavoura & $1897-$ & 1 & $\begin{array}{c}\text { Divulgação } \\
\text { científica na área de } \\
\text { agricultura }\end{array}$ & $\begin{array}{l}\text { Sociedade Nacional } \\
\text { de Agricultura }\end{array}$ \\
\hline Memórias do $10 \mathrm{C}$ & 1909- & 132 & $\begin{array}{l}\text { Disseminaçãao } \\
\text { científica }\end{array}$ & $\begin{array}{l}\text { Instituto Oswaldo } \\
\text { Cruz/Fundação } \\
\text { Oswaldo Cruz }\end{array}$ \\
\hline Paraná Médico & $1916-30(?)$ & 1 & $\begin{array}{c}\text { Divulgação } \\
\text { científica - órgão } \\
\text { de divulgação dos } \\
\text { trabalhos da } \\
\text { sociedade }\end{array}$ & $\begin{array}{l}\text { Sociedade de } \\
\text { Medicina do Paraná }\end{array}$ \\
\hline $\begin{array}{c}\text { Patologia Geral } \\
\text { Subtítulo: Revista de } \\
\text { Medina e Ciências } \\
\text { Afins }\end{array}$ & $1916-\quad(?)$ & 1 & $\begin{array}{l}\text { Disseminação } \\
\text { científica }\end{array}$ & \\
\hline Revista Med. Minas & $1908-22$ & 1 & $\begin{array}{l}\text { Divulgação } \\
\text { científica (para a } \\
\text { classe médica } \\
\text { mineira) }\end{array}$ & \\
\hline $\begin{array}{l}\text { Rev. Med. de São } \\
\text { Paulo }\end{array}$ & $1898-1914$ & 11 & $\begin{array}{l}\text { Disseminação } \\
\text { científica }\end{array}$ & \\
\hline $\begin{array}{l}\text { Rev. Soc. Bras. de Sci. } \\
\text { (continua como Rev. } \\
\text { de Ciências) }\end{array}$ & 1917-19 & 3 & $\begin{array}{l}\text { Disseminação } \\
\text { científica }\end{array}$ & $\begin{array}{c}\text { Academia Brasileira } \\
\text { de Ciências }\end{array}$ \\
\hline $\begin{array}{c}\text { Rev. Soc. Sci. de São } \\
\text { Paulo }\end{array}$ & $1905-13$ & 1 & $\begin{array}{l}\text { Disseminação } \\
\text { científica }\end{array}$ & $\begin{array}{l}\text { Sociedade Científica } \\
\text { de São Paulo }\end{array}$ \\
\hline $\begin{array}{l}\text { Rev. de Veterinária e } \\
\text { Zootécnica }\end{array}$ & $\begin{array}{c}1911-32 \\
\text { Substituída pela Rev. do } \\
\text { Depto }{ }^{\circ} \text { Nac. de Produção } \\
\text { Animal }\end{array}$ & 4 & $\begin{array}{l}\text { Divulgação } \\
\text { científica para } \\
\text { pecuária } \\
\text { (veterinária) }\end{array}$ & $\begin{array}{l}\text { Serviço do Ministério } \\
\text { de Agricultura } \\
\text { Indústria e Comércio }\end{array}$ \\
\hline Semana Médica & 1911-13 (?) & 1 & $\begin{array}{l}\text { Divulgação para a } \\
\text { classe médica }\end{array}$ & \\
\hline
\end{tabular}


Com relação às publicações do instituto em periódicos científicos estrangeiros, estas totalizam 36 artigos distribuídos entre vinte títulos, sendo seis periódicos alemães, totalizando 14 artigos; seis argentinos, totalizando dez artigos; cinco franceses, totalizando seis artigos; e três norte-americanos, totalizando seis artigos. O Quadro 7 detalha a distribuição de artigos por publicação. Estes são artigos relacionados às seguintes especialidades: protozoologia, parasitologia, bacteriologia e entomologia, na sua maioria sobre doenças infecciosas e parasitárias.

QUADRO 7

PERIÓDICOS ESTRANGEIROS NOS QUAIS OS CIENTISTAS DO IOC PUBLICARAM ARTIGOS (1900-17)

\begin{tabular}{|c|c|c|c|}
\hline $\begin{array}{c}\text { № DE } \\
\text { ORDEM }\end{array}$ & PERIÓDICOS & PAÍS & $\begin{array}{c}\text { No }=\text { DE } \\
\text { ARTIGOS }\end{array}$ \\
\hline 1 & Zentralbl. F. Bakt. & Alemanha & 5 \\
\hline 2 & Prensa Médica Argentina & Argentina & 4 \\
\hline 3 & Arch. F. Schiffs u. Tropen. & Alemanha & 3 \\
\hline 4 & Proc. Entomol. Soc. Wash. & EUA & 3 \\
\hline 5 & Bull. Soc. Pat. Exot. & França & 2 \\
\hline 6 & Archiv. F. Protistenk. & Alemanha & 2 \\
\hline 7 & New Orleans Med. \& Trop. Journal & EUA & 2 \\
\hline 8 & Bol. Inst. Bact. & Argentina & 2 \\
\hline 9 & Munch. Med. Wochen. & Alemanha & 2 \\
\hline 10 & Zeits. F. Hyg. Infekt. & Alemanha & 1 \\
\hline 11 & Bull. Inst. Pasteur & França & 1 \\
\hline 12 & Nouv. Iconog. Salpet. & França & 1 \\
\hline 13 & New Orleans Med. Surg. & EUA & 1 \\
\hline 14 & Anales Mus. Hist. Nat. & Argentina & 1 \\
\hline 15 & Zool. Jahrb. & Alemanha & 1 \\
\hline 16 & C. R. Soc. Biol. & França & 1 \\
\hline 17 & Semana Médica & Argentina & 1 \\
\hline 18 & Ann. De l'Inst. Pasteur & França & 1 \\
\hline 19 & Rev. Assoc. Med. Argentina & Argentina & 1 \\
\hline 20 & Rev. Univ. B. Aires. & Argentina & 1 \\
\hline TOTAL & & & 36 \\
\hline
\end{tabular}


A Figura 2 apresenta a distribuição geográfica dos artigos publicados no exterior. A Alemanha, como vimos, tem supremacia, com 14 artigos publicados de um total de 36, em um percentual de 39\%.

As características dos periódicos científicos estrangeiros nos quais os cientistas publicaram artigos vêm discriminadas no Quadro 8, sendo quase todos eles periódicos de disseminação científica.

FIGURA 2

DISTRIBUIÇÃO GEOGRÁFICA DOS ARTIGOS DE PERIÓDICOS PUBLICADOS NO EXTERIOR (1900-17)

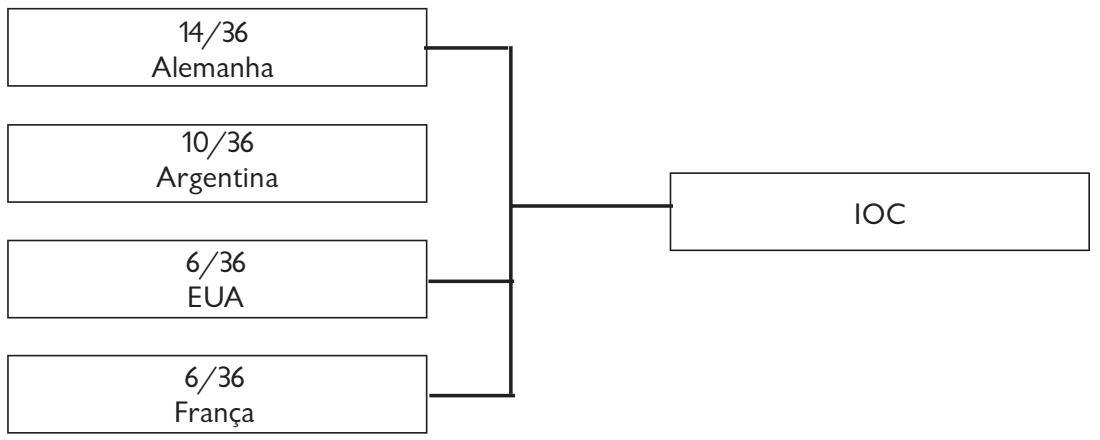

O Gráfico 1 apresenta a distribuição de todos os artigos de periódicos produzidos no período, ficando 39,6\% para o BrazilMédico, 36\% para as Memórias do IOC, 14,5\% para outras revistas brasileiras e 9,8\% para as revistas estrangeiras.

Os resultados deixam claro que os cientistas do IOC publicaram prioritariamente no Brasil. O percentual de artigos publicados no exterior é de 9,8\%, enquanto os publicados no Brasil totalizam 90,1\%.

Esse fato pode demonstrar que os cientistas estavam mais preocupados em publicar no Brasil, em dialogar com os cientistas brasileiros, já que suas linhas de pesquisa, como já mencionamos, estavam voltadas para a resolução de problemas brasileiros. Mas pode ser, simplesmente, que eles tivessem mais facilidade em publicar em periódicos nacionais.

As relações de co-autoria estão apresentadas no Sociograma 1.

\section{GRÁFICO I}

DISTRIBUIÇÃO POR PERIÓDICO OU GRUPO DE PERIÓDICOS DOS ARTIGOS*

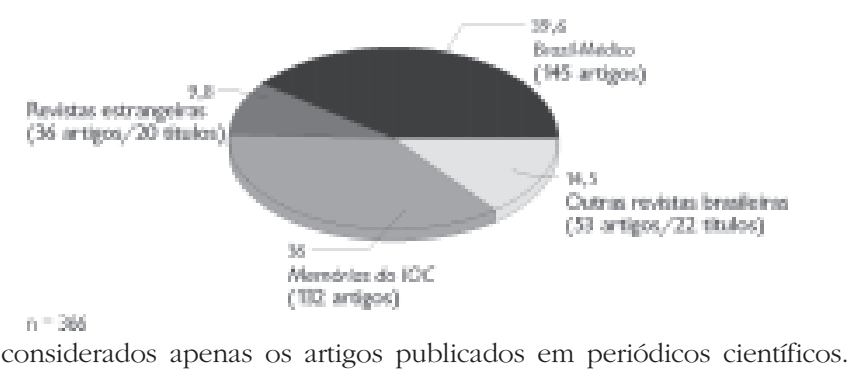


QUADRO 8

CARACTERÍSTICAS DOS PERIÓDICOS ESTRANGEIROS NOS QUAIS OS CIENTISTAS DO IOC PUBLICARAM SEUS ARTIGOS (1900-17)

\begin{tabular}{|c|c|c|c|c|}
\hline $\begin{array}{c}\text { TÍTULO } \\
\text { DO PERIÓDICO }\end{array}$ & $\begin{array}{c}\text { ANO } \\
\text { INÍCIO-FIM } \\
\text { DE } \\
\text { PUBLICAÇÃO }\end{array}$ & $\begin{array}{l}\text { NÚMERO } \\
\text { DE } \\
\text { ARTIGOS }\end{array}$ & $\begin{array}{c}\text { TIPO DE } \\
\text { PERIÓDICO }\end{array}$ & $\begin{array}{l}\text { LOCAL DE } \\
\text { PUBLICAÇÃO } \\
\text { CIDADE } \\
\text { PAÍS }\end{array}$ \\
\hline Anales Mus. Hist. Nat. & $1895-1929$ & 1 & $\begin{array}{l}\text { Disseminação } \\
\text { científica }\end{array}$ & $\begin{array}{l}\text { Buenos Aires } \\
\text { Argentina }\end{array}$ \\
\hline Annales de l'Institut Pasteur & $1887-1972$ & 1 & $\begin{array}{l}\text { Disseminação } \\
\text { científica }\end{array}$ & $\begin{array}{l}\text { Paris } \\
\text { França }\end{array}$ \\
\hline Archiv. f. Protistenk. & $1902-$ & 2 & $\begin{array}{l}\text { Disseminação } \\
\text { científica }\end{array}$ & $\begin{array}{c}\text { lena } \\
\text { Alemanha }\end{array}$ \\
\hline Archiv. f. Schiffs u. Tropenhygiene & $1847-1935$ & 3 & $\begin{array}{l}\text { Disseminação } \\
\text { científica }\end{array}$ & $\begin{array}{l}\text { Leipzig } \\
\text { Alemanha }\end{array}$ \\
\hline $\begin{array}{l}\text { Bol. Inst. Bact. (continua como Revista } \\
\text { del Inst. Bacteriológico del Dept }{ }^{\circ} \text { Nac. } \\
\text { de Higiene - 1917) }\end{array}$ & $1915-16$ & 2 & $\begin{array}{c}\text { Disseminação } \\
\text { científica }\end{array}$ & $\begin{array}{c}\text { Buenos Aires } \\
\text { Argentina }\end{array}$ \\
\hline Bull. Inst. Pasteur & 1903- & 1 & $\begin{array}{l}\text { Disseminação } \\
\text { científica }\end{array}$ & $\begin{array}{l}\text { Paris } \\
\text { França }\end{array}$ \\
\hline Bull. Soc. Pat. Exot. & 1908- & 2 & $\begin{array}{l}\text { Disseminação } \\
\text { científica }\end{array}$ & $\begin{array}{l}\text { Paris } \\
\text { França }\end{array}$ \\
\hline C. R. Soc. Biol. & $1849-\quad(?)$ & 1 & $\begin{array}{c}\text { Disseminação } \\
\text { científica }\end{array}$ & $\begin{array}{c}\text { Paris } \\
\text { França }\end{array}$ \\
\hline Munch. Med. Wochen & $1854-$ & 2 & $\begin{array}{c}\text { Disseminação } \\
\text { científica }\end{array}$ & $\begin{array}{l}\text { Munique } \\
\text { Alemanha }\end{array}$ \\
\hline New Orleans Med. Surg. & $1844-\quad(?)$ & 1 & $\begin{array}{l}\text { Disseminação } \\
\text { científica }\end{array}$ & $\begin{array}{c}\text { Nova Orleans } \\
\text { EUA }\end{array}$ \\
\hline New Orleans Med. \& Trop. Journal & & 2 & $\begin{array}{l}\text { Disseminação } \\
\text { científica }\end{array}$ & $\begin{array}{c}\text { Nova Orleans } \\
\text { EUA }\end{array}$ \\
\hline $\begin{array}{l}\text { Nouv. Iconog. Salpet. (absorvida pela } \\
\text { Revue Neurologique) }\end{array}$ & $1888-1918$ & 1 & $\begin{array}{l}\text { Disseminação } \\
\text { científica }\end{array}$ & $\begin{array}{c}\text { Paris } \\
\text { França }\end{array}$ \\
\hline Prensa Médica Argentina & $1914-83$ & 4 & $\begin{array}{l}\text { Disseminação } \\
\text { científica }\end{array}$ & $\begin{array}{l}\text { Buenos Aires } \\
\text { Argentina }\end{array}$ \\
\hline Proc. Entomol. Soc. Wash. & $1884-$ & 3 & $\begin{array}{l}\text { Disseminação } \\
\text { científica }\end{array}$ & $\begin{array}{l}\text { Washington } \\
\text { EUA }\end{array}$ \\
\hline Rev. Assoc. Med. Argentina & (?) $-1971 \quad(?)$ & 1 & $\begin{array}{l}\text { Disseminação } \\
\text { científica }\end{array}$ & $\begin{array}{l}\text { Buenos Aires } \\
\text { Argentina }\end{array}$ \\
\hline Rev. Univ. B. Aires & $1904-56$ & 1 & $\begin{array}{l}\text { Disseminação } \\
\text { científica }\end{array}$ & $\begin{array}{l}\text { Buenos Aires } \\
\text { Argentina }\end{array}$ \\
\hline Semana Médica & $1894-$ & 1 & $\begin{array}{l}\text { Disseminação } \\
\text { científica }\end{array}$ & $\begin{array}{l}\text { Buenos Aires } \\
\text { Argentina }\end{array}$ \\
\hline Zeits F. Hyg. Infekt. & $1886-91$ & 1 & $\begin{array}{c}\text { Disseminaçãao } \\
\text { científica }\end{array}$ & $\begin{array}{c}\text { Leipzig } \\
\text { Alemanha }\end{array}$ \\
\hline Zebtralbl. f. Bakt. & 1887- & 5 & $\begin{array}{l}\text { Disseminação } \\
\text { científica }\end{array}$ & $\begin{array}{c}\text { lena } \\
\text { Alemanha }\end{array}$ \\
\hline Zool. Jahrb. & 1886-1965 (?) & 1 & $\begin{array}{l}\text { Disseminação } \\
\text { científica }\end{array}$ & $\begin{array}{c}\text { lena } \\
\text { Alemanha }\end{array}$ \\
\hline
\end{tabular}




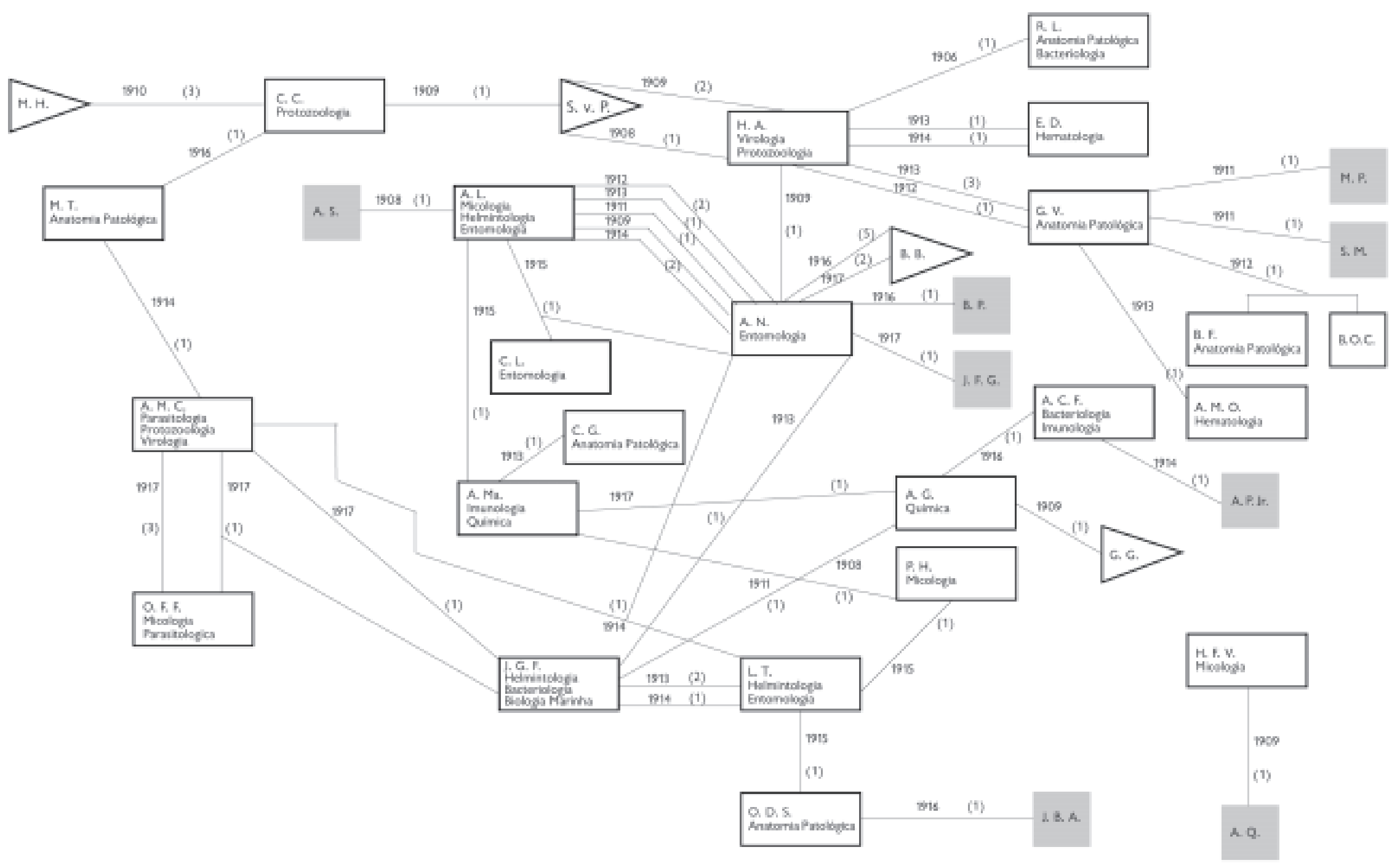


IOC
A. M. C. - Aristides Marques da Cunha
A. M. A. - Astrogildo Machado
L. T. - Lauro Travassos
A. G. - Alcides Godoy
C. G. - César Guerreiro
A. N. - Arthur Neiva
M. T - Magarinos Torres
O. F. F. - Olympio da Fonseca Filho
A. C. F. - Antonio Cardoso Fontes
J. G. F. - José Gomes de Faria
H. F. V. - Henrique Figueiredo de Vasconcelos
H. A. - Henrique Aragão
O. D. S. - Oscar D'utra e Silva
R. L. - Henrique da Rocha Lima
C. L. - Costa Lima
A. L. - Adolpho Lutz
C. C. - Carlos Chagas
P. H. - Parreiras Horta
G. V. - Gaspar Vianna
B. F. - Burle de Figueiredo
B. O. C. - Bento Oswaldo Cruz (filho de Oswaldo Cruz)
E. D. - Ezequiel Dias
A. M. - Arthur Neiva

Não pertencem ao quadro:
A. S. - Alfonso Splendore
A. Q. - Arnaldo Quintella
M. P. - Miguel Pereira
B. P. - Belisário Penna
S. M. - Sylvio Moniz
J. B. A. - José Bernardino Arantes
A. P. Jr. - A. Pinto Jr.
J. F. G. - J. Florêncio Gomes

Estrangeiros:

S. v. P. - Stanislas von Prowazek (alemão)

G. G. - Gustav Giemsa (alemão)

M. H. - Max Hartmann (alemão)

B. B. - Belarmino Barbará (argentino)

$\square$ Representa pesquisador do IOC

$\triangle$ Representa pesquisador estrangeiro

Representa pesquisador brasileiro não pertencente aos quadros do $10 \mathrm{C}$

(1) Representa quantidade de trabalhos publicados

Representa o ano da publicação

Além de quarenta casos de co-autoria entre cientistas do IOC, encontramos 23 casos de co-autoria estabelecida, no período, entre cientistas do IOC e de outras instituições. A colaboração externa nacional não é muito significativa: foram registrados apenas nove caso desse tipo. Isso talvez se explique porque, àquela época, não existia ainda um grande número de pesquisadores na área, caracterizando-se o pioneirismo do IOC até no papel de formador de massa crítica, ainda quase inexistente no país.

Os pesquisadores estrangeiros com os quais os pesquisadores do IOC publicaram em conjunto são: Stanislas Von Prowazek, Gustav Giemsa e Max Hartmann, cientistas alemães, que como já foi mencionado, estiveram no IOC ensinando e pesquisando. E o entomólogo argentino Belarmino Barbará, que publicou sete trabalhos com Arthur Neiva, no período. 
Pelos resultados encontrados no tocante aos casos de co-autoria ocorridos, pudemos constatar que, no período, foi desenvolvida, no interior da instituição, grande quantidade de trabalhos em conjunto, e que alguns cientistas serviram de ponto de ligação entre várias especialidades e cientistas. Nesse tipo de atividade destacaram-se: Henrique Aragão, Arthur Neiva, José Gomes de Faria, Gaspar Vianna e Adolpho Lutz. A maioria dos cientistas do IOC publicou trabalhos em co-autoria: dos 29 cientistas estudados, 22, isto é, 76\%, publicaram pelo menos um trabalho em conjunto com outro cientista.

No tocante às citações contidas nos trabalhos (Quadro 9), o maior percentual cabe às citações a periódicos alemães, ficando as citações a periódicos brasileiros em terceiro lugar. Em relação, porém, à média de citações por título, os periódicos brasileiros alcançaram uma das maiores médias, seguidos pelos periódicos alemães e franceses. É impressionante a quantidade e a variedade de periódicos citados, bem como a sua dispersão geográfica. Alguns dos periódicos citados eram editados em colônias francesas, holandesas e inglesas, alguns eram editados em países africanos e da Europa Oriental. Há ainda citações a periódicos publicados em outros países da América Latina. O total de periódicos citados é de 487. Destes, 67\% estavam disponíveis na biblioteca de Manguinhos.

QUADRO 9

\section{DISTRIBUIÇÃO GEOGRÁFICA E POR TÍTULOS DE PERIÓDICOS DAS CITAÇÕES FEITAS PELOS CIENTISTAS DO IOC A PERIÓdICOS CIENTÍFICOS (1900-17)}

\begin{tabular}{lcccc}
\hline $\begin{array}{l}\text { PAís DE } \\
\text { ORIGEM }\end{array}$ & $\begin{array}{c}\text { TítULOS DE } \\
\text { PERIÓDICOS } \\
\text { CITADOS }\end{array}$ & $\begin{array}{c}\text { CITAÇÕES } \\
\text { No }\end{array}$ & $\begin{array}{c}\text { MÉd } \\
\text { (\%) }\end{array}$ & $\begin{array}{c}\text { MÉ DE } \\
\text { CITÇÕES POR } \\
\text { TÍTULO }\end{array}$ \\
\hline Alemanha & 112 & & & 9 \\
França & 62 & 1.017 & $(36,9 \%)$ & 8 \\
Brasil & 34 & 501 & $(18,2 \%)$ & 10,5 \\
Reino Unido & 38 & 356 & $(12,9 \%)$ & 6,8 \\
EUA & 60 & 259 & $(9,4 \%)$ & 3 \\
Áustria & 10 & 182 & $(6,6 \%)$ & 6,5 \\
Itália & 34 & 65 & $(2,3 \%)$ & 1,8 \\
Índia & 7 & 62 & $(2,2 \%)$ & 4,8 \\
Argentina & 14 & 34 & $(1,2 \%)$ & 2 \\
Austrália & 6 & 29 & $(1,0 \%)$ & 3,2 \\
Bélgica & 7 & 19 & $(0,7 \%)$ & 2,4 \\
Egito & 6 & 17 & $(0,6 \%)$ & 3 \\
Guiana Inglesa & 1 & 18 & $(0,6 \%)$ & 15 \\
Suécia & 3 & 15 & $(0,5 \%)$ & 4,3 \\
Suíça & 5 & 13 & $(0,5 \%)$ & 2,6 \\
Rússia & 3 & 13 & $(0,5 \%)$ & 2,7 \\
Peru & 2 & 8 & $(0,3 \%)$ & 3,5 \\
Filipinas & 2 & 7 & $(0,2 \%)$ & 3,5
\end{tabular}


QUADRO 9 (Cont.)

\begin{tabular}{|c|c|c|c|c|}
\hline \multirow{2}{*}{$\begin{array}{l}\text { PAÍS DE } \\
\text { ORIGEM }\end{array}$} & \multirow{2}{*}{$\begin{array}{l}\text { TÍTULOS DE } \\
\text { PERIÓDICOS } \\
\text { CITADOS }\end{array}$} & \multicolumn{2}{|c|}{ CITAÇÕES } & \multirow{2}{*}{$\begin{array}{c}\text { MÉDIA DE } \\
\text { CITAÇÕES POR } \\
\text { TÍTULO }\end{array}$} \\
\hline & & $\mathbf{N}^{\circ}$ & (\%) & \\
\hline Polônia & 3 & 7 & $(0,2 \%)$ & 2,3 \\
\hline Sri Lanka & 2 & 6 & $(0,2 \%)$ & 3 \\
\hline Indochina & 1 & 6 & $(0,2 \%)$ & 6 \\
\hline Tanzânia & 2 & 5 & $(0,2 \%)$ & 2,5 \\
\hline Argélia & 2 & 5 & $(0,2 \%)$ & 2,5 \\
\hline Canadá & 2 & 5 & $(0,2 \%)$ & 2,5 \\
\hline África do Sul & 4 & 5 & $(0,2 \%)$ & 1,25 \\
\hline Tchecoslováquia & 1 & 4 & $(0,1 \%)$ & 4 \\
\hline Portugal & 2 & 4 & $(0,1 \%)$ & 2 \\
\hline Japão & 2 & 3 & $(0,1 \%)$ & 1,5 \\
\hline Havaí & 2 & 3 & $(0,1 \%)$ & 1,5 \\
\hline Colômbia & 3 & 3 & $(0,1 \%)$ & 1 \\
\hline Costa Rica & 1 & 2 & $(0,07 \%)$ & 2 \\
\hline Illhas Maurício & 1 & 2 & $(0,07 \%)$ & 2 \\
\hline China & 1 & 2 & $(0,07 \%)$ & 2 \\
\hline Noruega & 1 & 2 & $(0,07 \%)$ & 2 \\
\hline Tunísia & 1 & 2 & $(0,07 \%)$ & 2 \\
\hline Hungria & 1 & 2 & $(0,07 \%)$ & 2 \\
\hline Bolívia & 2 & 2 & $(0,07 \%)$ & 1 \\
\hline Cuba & 2 & 2 & $(0,07 \%)$ & 1 \\
\hline México & 1 & 1 & $(0,04 \%)$ & 1 \\
\hline Holanda & 1 & 1 & $(0,04 \%)$ & 1 \\
\hline Uruguai & 1 & 1 & $(0,04 \%)$ & 1 \\
\hline Panamá & 1 & 1 & $(0,04 \%)$ & 1 \\
\hline Paraguai & 1 & 1 & $(0,04 \%)$ & 1 \\
\hline Sudão & 1 & 1 & $(0,04 \%)$ & 1 \\
\hline Dinamarca & 1 & 1 & $(0,04 \%)$ & 1 \\
\hline Venezuela & 1 & 1 & $(0,04 \%)$ & 1 \\
\hline Jamaica & 1 & 1 & $(0,04 \%)$ & 1 \\
\hline Congo francês & 1 & 1 & $(0,04 \%)$ & 1 \\
\hline Não identificados & 35 & 52 & $(1,9 \%)$ & \\
\hline TOTAIS & 487 & 2.756 & $(99,6 \%)$ & \\
\hline
\end{tabular}

Se, como vimos, os cientistas de Manguinhos publicaram prioritariamente no Brasil, no tocante à citação, o movimento invertese. Eles citam mais os periódicos estrangeiros: alemães e franceses. A preponderância de citações a periódicos alemães é grande, chegando ao dobro do percentual atribuído aos periódicos franceses e quase ao triplo do percentual conferido aos periódicos brasileiros.

Isso pode ser explicado, parcialmente, pelo convívio dos cientistas do IOC com os pesquisadores alemães que visitaram o instituto. Além disso, alguns cientistas de Manguinhos estiveram na Alemanha, visitando instituições científicas, estudando e trabalhando. Um deles, o dr. Rocha Lima, chegou a lecionar na Universidade de Hamburgo, 
além de ter dirigido a Divisão de Anatomia Patológica do Instituto de Higiene Tropical da mesma cidade.

Apesar de o Instituto Pasteur ter servido de modelo organizativo para o IOC, e de a pesquisa em Manguinhos ter sofrido influência da medicina pasteuriana, os periódicos mais citados foram os alemães, e não os franceses. Talvez isso não se explique apenas pelas ligações entre os cientistas do IOC e os cientistas e instituições alemães. Pode ser que as áreas em que os cientistas do instituto mais atuavam, no caso, como se viu, a anatomia patológica, a Alemanha estivesse mais avançada.

Segundo Schwartzman (1979), duas tradições científicas irão se cruzar em Manguinhos: a francesa e a alemã. Pelo levantamento realizado, contudo, fica clara a predominância de citações a periódicos alemães por parte dos cientistas do instituto.

De qualquer modo, não é surpreendente que os cientistas do IOC fossem buscar em alguns países europeus informações para suas pesquisas, uma vez que esses países eram os grandes produtores de saber científico na época. Contudo, como frisamos anteriormente, os periódicos científicos brasileiros receberam, ainda assim, um grande número de citações, sendo que grande parte delas de artigos dos próprios cientistas do instituto. A autocitação pode ser explicada porque esses pesquisadores eram pioneiros no Brasil nas áreas em que pesquisavam.

Acreditamos, portanto, que as citações podem refletir uma série de comportamentos informacionais. Elas podem denotar tanto a busca de conhecimentos quanto o desejo de respaldo científico; tanto podem demonstrar atualização em uma determinada área quanto o reconhecimento de prioridade em descobertas, entre outros.

\section{Conclusão}

O presente estudo permite concluir que a produção científica publicada pelos cientistas do IOC no período considerado acompanhou o crescimento de Manguinhos ao longo dos anos e foi um efeito de sua consolidação.

Conclui-se ainda que essa produção era caracteristicamente de disseminação científica, com uma pequena parcela $-5 \%$ do total de artigos publicados no Brasil - publicada em órgãos de divulgação voltados para a agricultura e pecuária, ou em órgãos de divulgação que representam entidades médicas. A produção geral do instituto foi preponderantemente publicada no Brasil, com o percentual de artigos publicados no país alcançando 90,1\% da produção total de artigos.

No tocante à produção publicada no exterior, os periódicos alemães tiveram a supremacia, com um percentual de 39\% dos artigos publicados, seguidos pelos periódicos argentinos, em um percentual de $28 \%$, o que provavelmente ocorreu pelos contatos que foram estabelecidos no 
período tanto com a Alemanha - através do intercâmbio com instituições e cientistas alemães — quanto com a Argentina — através de parceria entre Arthur Neiva, responsável por 80\% dos artigos publicados naquele país, e o entomólogo Belarmino Barbará.

Pela quantidade de casos de co-autoria registrados, pôde-se concluir que os cientistas do IOC efetivamente trabalhavam em equipe, havendo inclusive a conjugação de pesquisadores de especialidades distintas desenvolvendo trabalhos em conjunto. As Co-autorias entre pesquisadores do IOC e pesquisadores estrangeiros atestam a colaboração internacional que o instituto estabeleceu no período.

Conclui-se também que os cientistas do instituto não atuaram apenas em suas respectivas especialidades, desenvolvendo pesquisas, produzindo medicamentos e publicando. Eles envolveram-se também em atividades de docência e assumiram cargos em órgãos públicos nas áreas da saúde pública e das ciências biomédicas.

A dispersão geográfica e a grande quantidade de periódicos citados dá uma idéia da gama imensa de informações a que os cientistas tinham acesso.

O fato de a Biblioteca de Manguinhos dispor de $67 \%$ do material citado pelos pesquisadores atesta a preocupação do instituto em fornecer fontes de informação para seus cientistas. Dispor de um acervo tão rico é também indicador do estado de florescimento e de consolidação no qual se encontrava a instituição.

O comportamento 'citacional' dos cientistas no período apresentouse sob dois aspectos:

- A predominância de citações a periódicos europeus, o que acreditamos denotar a busca de conhecimentos consolidados, ou de conhecimentos de frente de pesquisa em suas especialidades.

- O grande número de citações, ainda assim, atribuídos a periódicos brasileiros, tratando-se, na maioria das vezes, de autocitações, o que se justifica pelo pioneirismo das pesquisas realizadas em suas especialidades no Brasil.

Conclui-se, portanto, que motivos diferentes devem ter orientado as citações de periódicos estrangeiros e brasileiros. Paula Mello (1990, p. 79) analisa outro desses casos em sua dissertação de mestrado sobre os pesquisadores brasileiros em botânica, no ano de 1989. Segundo a autora, esses pesquisadores lêem, no seu dia-adia, a literatura que lhes é mais acessível e subjetivamente atraente: a literatura brasileira. Ela assinala ainda que esses pesquisadores "consideram o periódico nacional muito importante para a área, embora tenham indicado o periódico estrangeiro como o mais importante para o desenvolvimento de seu trabalho". Este caso e as conclusões anteriormente expostas levam a acreditar que o uso de análise de citação deve estar todo o tempo vinculado ao contexto 
em estudo, de modo a que os dados coletados não sejam mal interpretados.

Ficou caracterizado, portanto, que o comportamento dos cientistas do IOC, no período estudado, estava voltado para o exterior, quando queriam buscar informação consolidada, e voltado para o Brasil, quando queriam transmitir informação.

\section{REFERÊNCIAS BIBLIOGRÁFICAS}

Aragão, Henrique de B. R.

1950

Aragão, Henrique de B. R.

1945

Azevedo, Fernando de 1955

Azevedo, Fernando de 1944

Benchimol, Jaime L. (org.) 1990

Benchimol, Jaime L. et al. 1990

Braga, Gilda et al. jan.-jun. 1982 1963

Christovão, Heloisa T. 1989

Christovão, Heloisa T. 1979

Costa Lima, Ângelo

Moreira da 1964

Coura, José $\mathrm{R}$. s. d.

Dantes, Maria A. M. 1979-80

Dias, Arlete A. dos S. R. et al. 1990
'Notícia histórica sobre a fundação do Instituto Oswaldo Cruz: Instituto de Manguinhos'. Memórias do IOC, vol. 48, pp. 1-50.

'Necrológico do doutor Astrogildo Machado'. Memórias do IOC, nำ2, pp. 1-4.

'Introdução'. As ciências no Brasil.

Rio de Janeiro, Melhoramentos, vol. 1.

A cultura brasileira.

São Paulo, Companhia Editora Nacional, vol. 3.

Manguinhos do sonho à vida: a ciência na belle époque. Rio de Janeiro, Casa de Oswaldo Cruz.

Lauro Travassos: centenário 1890-1990.

Rio de Janeiro, Casa de Oswaldo Cruz.

'Diretrizes para avaliação de periódicos científicos e técnicos brasileiros'.

Revista Latino-Americana de Documentação, vol. 2, noำ 1, pp. 27-31.

Catálogo de Periódicos da Biblioteca do Instituto Oswaldo Cruz. Rio de Janeiro, Instituto Oswaldo Cruz, 331p.

O processo de comunicação científica e a transferência de informação em ciência e tecnologia. Rio de Janeiro, UFRJ.

'Da comunicação informal à comunicação formal: identificação da frente de pesquisa através de filtros de qualidade Ciência da Informação, vol. 8, no 1, pp. 3-36.

Bol. Campo, vol. 20, nำ179, pp. 11-2.

Carlos Bastos Magarinos Torres. s. 1.

'Institutos de pesquisa científica no Brasil.

Em M. G. Ferri et al. (org.), História das ciências no Brasil. São Paulo, Edusp/EPU/CNPq, cap. 8.

Lauro Travassos (1890-1900): bibliografia.

Rio de Janeiro, Fiocruz. 


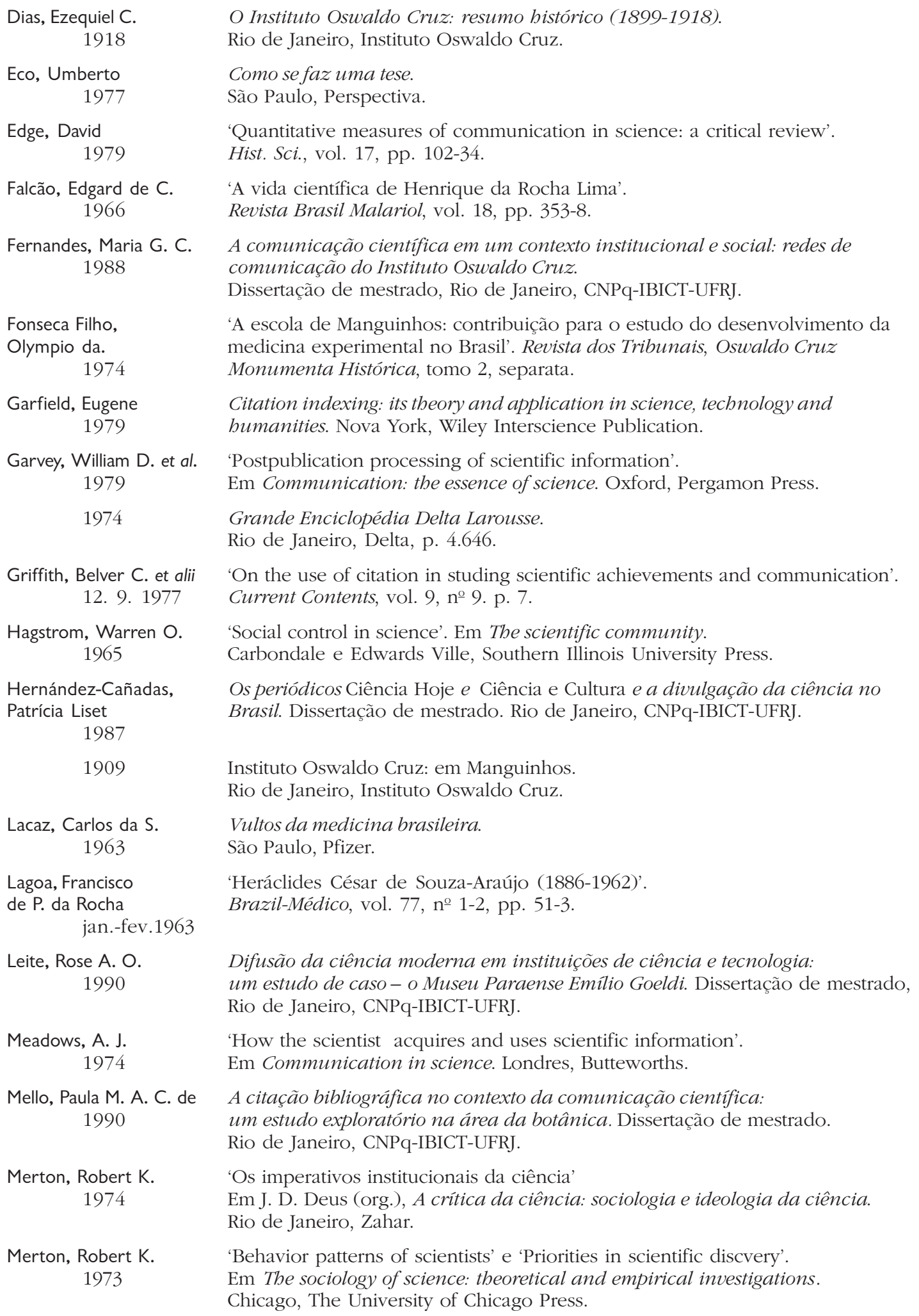


Mikhailov, A. l. et al. 'Scientific communication'.

1984

Em Scientific communication and informatics.

Arllington, Information Resources Press.

Morel, Regina L. de M. 1979

Mulkay, M. J. 1977

Narin, Francis et al. 1977

Narin, Francis et alii 1976

Neiva, Arthur

Oliveira, José C. de 1987

Polanyi, Michael 1969

Ravetz, J. R. 1979

Reis José

Reis, José

Schwarcz, Lilia

1993

Schwartzman, Simon 1979

Silveira, J. Cardoso

Fontes

Smith, L.

Stepan, Nancy

1976

Velho, Lea. 1986

Velho, Lea. 1985

Vieira Filho, J. J.

Ziman, J.

Oct. 1969

Ciência e Estado: a política científica no Brasil. São Paulo, T. A. Queiroz.

'Sociology of scientific research community'.

Em I. Spiegel-Rösing et al. (org.), Science, technology and society: a cross disciplinary perspective. Londres, Sage Publications.

'Bibliometrics'. Em M. E. Williams (org.), Annual Review of Information Science \& Technology. White Plains; Nova York, Knowledge Industry Publications.

Evaluative bibliometrics: the use of publications and citations analysis in the evaluation of scientific activity. Cherry Hill, Nova Jersey, Computer Horizons, Inc.

'Adolpho Lutz (1855-1940)'.

Memórias do IOC, vol. 36, n⿳ำ 1, pp. 1-23.

Ciência no Brasil monárquico: 1820-1870.

Rio de Janeiro, MCT/CNPq/Mast.

'The republic of science: its political and economic theory'. Em E. Shills (org.), Criteria for scientific development, public policy and national goals. Cambridge, Mass., MIT Press.

'The protection of property'. Em Scientific knowledge and its social problems. Nova York, Oxford University Press.

'Rocha Lima, o homem e a obra'.

Ciência e Cultura, vol. 28, nำ 4, pp. 463-79.

'Henrique de Aragão. Cientista dos maiores no mundo'. Folha de São Paulo. No mundo da ciência.

O espetáculo das raças: cientistas, instituições e questão racial no Brasil

1870-1930. São Paulo, Companhia das Letras.

Formação da comunidade científica no Brasil. São Paulo/Rio de Janeiro, Ed. Nacional/Finep.

Arquivos Brasileiros de Tuberculose e Doenças do Tórax, vol. 38, pp. 63-70.

'Citation analysis'.

Library Trends, vol. 30, nำ, pp. 83-106.

Gênese e evolução da ciência brasileira:

Oswaldo Cruz e a política de investigação científica e médica.

Rio de Janeiro, Artenova/Fundação Oswaldo Cruz.

'The meaning of citation in the context of a scientifically peripheral country'. Scientometrics, vol. 9, no 1-2, pp. 71-89.

'Como medir a ciência?'.

Rev. Bras. de Tec., vol. 16, nำ 1, pp. 35-41.

Antonio Fontes e a sua obra.

Rio de Janeiro, Typographia e Papelaria Coelho.

'Information, communication, knowledge'.

Nature, vol. 224, no 5217, pp. 318-24.

Recebido para publicação em junho de 2000.

Aprovado para publicação em abril de 2001. 